\title{
JEANYVES GUÉRIN, Littérature du politique au XXe siècle. De Paul Claudel à Jules Roy
}

\section{Monia Mezzetti}

\section{(2) OpenEdition}

\section{Journals}

\section{Edizione digitale}

URL: https://journals.openedition.org/studifrancesi/45458

DOI: 10.4000/studifrancesi.45458

ISSN: 2421-5856

\section{Editore}

Rosenberg \& Sellier

\section{Edizione cartacea}

Data di pubblicazione: 1 août 2021

Paginazione: 401

ISSN: 0039-2944

\section{Notizia bibliografica digitale}

Monia Mezzetti, «JEAnYves guérin, Littérature du politique au xxe siècle. De Paul Claudel à Jules Roy», Studi Francesi [Online], 194 (LXV | II) | 2021, online dal 01 septembre 2021, consultato il 15 octobre 2022. URL: http://journals.openedition.org/studifrancesi/45458 ; DOI: https://doi.org/10.4000/studifrancesi. 45458

Questo documento è stato generato automaticamente il 15 octobre 2022.

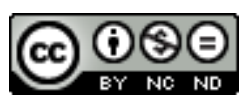

Creative Commons - Attribuzione - Non commerciale - Non opere derivate 4.0 Internazionale - CC BYNC-ND 4.0

https://creativecommons.org/licenses/by-nc-nd/4.0/ 


\title{
JEANYVES GUÉRIN, Littérature du politique au XX siècle. De Paul Claudel à Jules Roy
}

\author{
Monia Mezzetti
}

\section{NOTIZIA}

JEANYVES GUÉRIN, Littérature du politique au XXe siècle. De Paul Claudel à Jules Roy, Paris, Honoré Champion, 2020, 254 pp.

1 In questo saggio Jeanyves Guérin, professore emerito di Letteratura Francese alla Sorbonne Nouvelle, offre la lettura in chiave politica di alcune delle maggiori opere del Ventesimo secolo con lo scopo di affrancarle dalla definizione semplicistica di opere politiche. Forte delle sue ampie conoscenze, l'A. mette in guardia dall'accostamento di testi e autori agli schieramenti politici: in primo luogo, per il carattere pericolosamente riduttivo di questa operazione che, come tale, non darebbe conto della complessità semantica propria della letteratura (p. 21); in secondo luogo, perché storicamente sono stati pochi gli scrittori ad aver aderito a un partito o ad avervi militato e quindi, a maggior ragione, non può essere estesa alle loro opere l'eventuale etichetta "di destra" o "di sinistra" (p. 243); infine, perché i testi, oltre a non coincidere con i loro artefici, sono piuttosto rapportabili a delle tappe del loro itinerario umano, intellettuale e sociale, ovvero ne costituiscono una rappresentazione parziale (p. 23).

La selezione dei testi spazia dal genere narrativo a quello teatrale, fino alla memorialistica e propone autori anagraficamente distanti e profondamente diversi per orientamento politico. Non per questo però la sua inevitabile eterogeneità disorienta il lettore; al contrario, risulta stimolante, nella misura in cui riesce a ben dimostrare la validità del progetto di ricerca e della proposta di interpretazione. Il corpus oggetto di studio comprende: Tête d'or di Claudel (cap. 1), Les dieux ont soif di Anatole France (cap. 2), La condition humaine e L'espoir di Malraux (cap. 3 e cap. 4), le pièces di Anouilh (cap. 5 
e cap. 10) e quelle di Giraudoux (cap. 6), Le journal des années noires di Guéhenno (cap. 7), Les mains sales di Sartre (cap. 8), Bande à part di Jacques Perret (cap. 9), Les racines du ciel di Roman Gary (cap. 11), La guerre d'Algérie di Jules Roy (cap. 12). La ricerca risulta ben documentata e condotta con rigore, mentre non sono chiare le ragioni della trattazione della produzione di Malraux e di Anouilh in due capitoli separati ciascuno, quando forse più auspicabile sarebbe stata una loro analisi complessiva.

Il presupposto della rilettura operata da Guérin è che la scrittura, in quanto forma d'arte, va naturalmente incontro a una metamorfosi (p. 22), in virtù della quale l'interesse per l'opera letteraria si mantiene intatto nel tempo, oppure viceversa scema o si riaccende, e con esso la percezione del suo significato, anche politico. In altre parole, il valore di un'opera risulta relativo, in quanto strettamente collegato al contesto storico-culturale in cui vive l'autore. Coerentemente ne discende allora, come osserva acutamente l'A., che la lettura politica consiste anch'essa in una rilettura. Di grande interesse è anche l'analisi condotta sul destino altro delle opere originariamente engagées. Paradigmatici sono i casi di Giraudoux e Anouilh. La produzione del primo, di simpatie socialiste, è in parte vieillie poiché connessa a un contesto storico-culturale non più attuale, ma torna nuovamente d'interesse in ragione della presenza di elementi universali, transnazionali e grazie alla sua capacità di intercettare determinati temi contemporanei: così, La guerre de Troie n'aura pas lieu continua ad essere letta per il suo messaggio pacifista, data la minaccia costante di nuovi conflitti, mentre La folle de Chaillot lo è per la sua vena ecologista. Anouilh, invece, «anarchiste de droite» (p. 247), conosce oggi un nuovo successo per effetto di una lettura delle sue pièces (Antigone, L'alouette, Becket) più sensibile alle qualità artistiche che all'originaria vena polemica. Completano il volume l'apparato bibliografico (pp. 249-251) e l'Indice (pp. 243-259). 